\title{
Numerical Simulation of Airflow Organization and Temperature Distribution in Bulk Curing Barn
}

\author{
Yong-qiao WANG, Yan-qiong LI, Yan ZHAO \\ Yunnan Agricultural University, Kunming 650201,China \\ w7y7q7@126.com
}

Keywords: Bulk curing barn; Temperature field; Air flow distribution; Numerical simulation

\begin{abstract}
The tobacco leaf baking quality can be effectively improved on one hand, and overall baking time can be shortened to certain extent on the other hand by improving temperature in curing barn and uniformity of airflow organization distribution, thereby lowering energy consumption of baking. In the paper, bulk standard curing barn is regarded as simulate research object for establishing 3D model of air flow in bulk curing barn tobacco container. Numerical simulation is implemented on temperature filed and velocity field in curing barn in details. Rational air output of bulk curing barn can be obtained. Related numerical simulation results can provide reference for bulk curing barn structure size, airflow organization distribution optimization and circulating fan model selection.
\end{abstract}

\section{Introduction}

Since forced circulation hot air system is adopted in bulk curing barn, labor and time can be saved. The tobacco leaf quality is excellent after baking. Therefore, it is popularized and applied both at home and abroad. Bulk curing barn has become the development direction of flue-cured tobacco baking equipment in China [1] since the 21st century. If temperature field distribution is uneven in curing barn, the tobacco leaf baking quality will be affected, thereby increasing invalid heat increase.

CFD technology and its commercial software have been widely used in forecasting indoor thermal and humid environment, evaluating ventilation effect, and improving air supply and return system design in ventilation system [2]. The velocity field and temperature field in the curing barn are numerically analyzed through reasonably simplifying the model and using FLUENT software aiming at bulk curing barn. Factors affecting velocity field and temperature field can be obtained by analysis. Existing problems of bulk curing barn can be solved and improved in a targeted mode, thereby the purpose of improving baking quality of tobacco leaf can be achieved.

\section{Calculation model}

\section{Study object}

Tobacco container of bulk curing barn is regarded as study object of numerical simulation. The tobacco container has net length of $8 \mathrm{~m}$, width of $2.7 \mathrm{~m}$ and height of $3.5 \mathrm{~m}$, which can contain fresh tobacco leaf by more than $4500 \mathrm{~kg}$. Air supply mode belongs to upward supply and lower return mode. The air inlet is installed below the top plate of tobacco container. The air return channel is set on the lower portion of tobacco container. Hot air enters the upper tobacco layer through air inlet, which enters the air return channel through the tobacco layer from top to bottom. Then, the exhausted humid and thermal air can be supplied to heated air room (during internal circulation) through air return channel and discharged out of the curing barn through humidity elimination window (during humidity elimination). Curing barn is in the no-load state during the calculation process. 


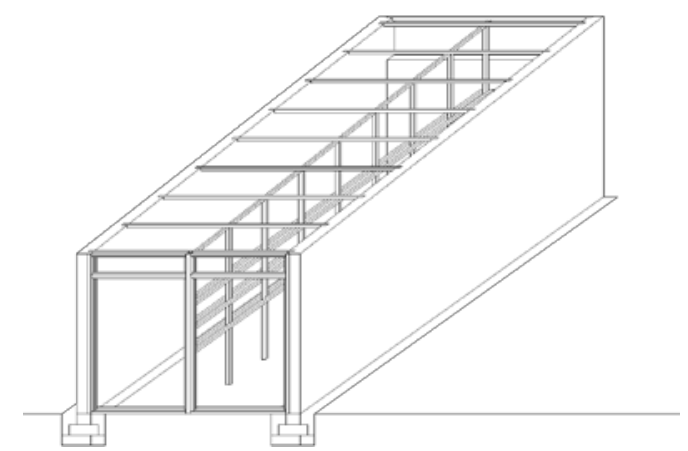

\section{Control equation}

Figure 1. Schematic diagram of bulk standard tobacco container

In the paper, $\mathrm{k}-\varepsilon$ two-equations $3 \mathrm{D}$ turbulent flow model is adopted. The following hypothesis is made in order to simplify problems [3].

a) Air in the curing barn belongs to incompressible fluid, and conforms to Boussinesq hypothesis. It is believed that fluid density changes only affect floating force production;

b) Air flow state belongs to steady turbulent flow in curing barn;

c) It is assumed that the flow field in the curing barn has high turbulent Reynolds number Re, and fluid is isotropic;

d) Thermal radiation among walls, roofs and solid surfaces is ignored, and air in the curing barn belongs to radiation transparent medium;

e) Dissipation heat caused by viscous force power of fluid can be ignored;

f) Influence of air leakage is not considered. It is believed that the curing barn has excellent air tightness.

Air flow and heat transfer mathematical model in the curing barn is described in the tensor form according to the above assumptions:

\section{Boundary conditions}

a) Time condition: external environment temperature is basically kept at a fixed value within certain time period in order to stabilize heat conduction process, therefore the temperature on the outer surface of curing barn wall is also basically kept at a fixed value, namely wall boundary condition belongs to the first kind of boundary condition. External environment temperature is the Kunming average temperature of $18.5{ }^{\circ} \mathrm{C}$ in October 2009 according to the meteorological data of China Meteorological Administration. The temperature on the outer surface of the wall is $34.93{ }^{\circ} \mathrm{C}$. The roof outside surface temperature is $33.28{ }^{\circ} \mathrm{C}$. The floor and tobacco container shelf are set as adiabatic boundary condition.

b) Inlet boundary: air supply velocity direction of curing barn air supply port is along the positive direction of $\mathrm{x}$ axis.

c) Outlet boundary: air return port is also regarded as pressure outlet. Fully developed flow unilateralization treatment is adopted. The temperature and velocity of air return port can be customized by the system according to boundary condition.

\section{Meshing and numerical solution method}

In the paper, model is established according to bulk standard tobacco container. The air supply port is set below the top plate of tobacco container and on the top end of heat insulation wall. The specifications are shown as follows: $2.7 \mathrm{~m} * 0.4 \mathrm{~m}$. The air return port is set at the bottom end of heat insulation wall according to specification of $1.4 \mathrm{~m} * 0.4 \mathrm{~mm}$. One humidity elimination port is respectively set on both sides of air return port according to specification of $0.4 \mathrm{~m} * 0.4 \mathrm{~m}$. The auxiliary humidity elimination port is set on the upper portion of two split gates.

GAMBIT is used for geometric modeling and meshing on tobacco container under rectangular coordinate system. TGrid meshing format is applied, and mesh number is 370078. Control volume method discrete control differential equation based on staggered grid is utilized. SIMPLE algorithm is adopted to solve the discrete control equation [5]. 


\section{Simulation result analysis}

Supply air temperature is set as $40{ }^{\circ} \mathrm{C}$, air output is $13000 \mathrm{~m} 3 / \mathrm{h}$, and distribution condition of velocity field and temperature field in the curing barn are shown in the following figure:

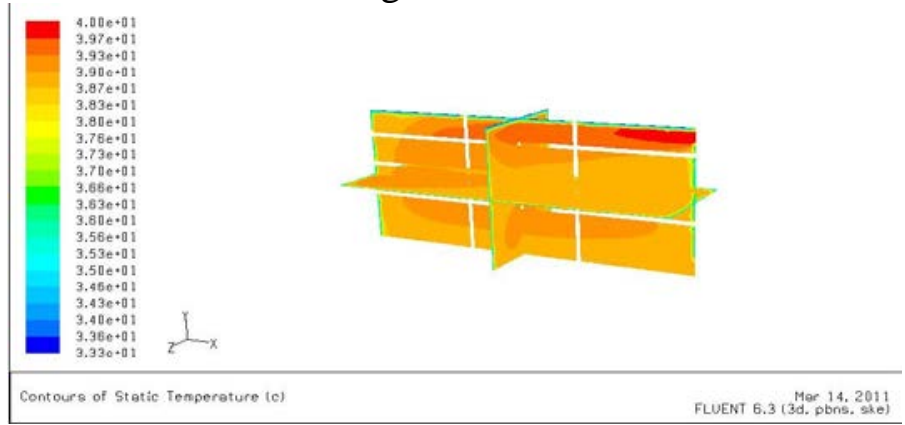

Figure 2. Temperature distribution in the curing cure at air supply temperature of $40^{\circ} \mathrm{C}$ and air output of $13000 \mathrm{~m} 3 / \mathrm{h}$ (unit: ${ }^{\circ} \mathrm{C}$ )

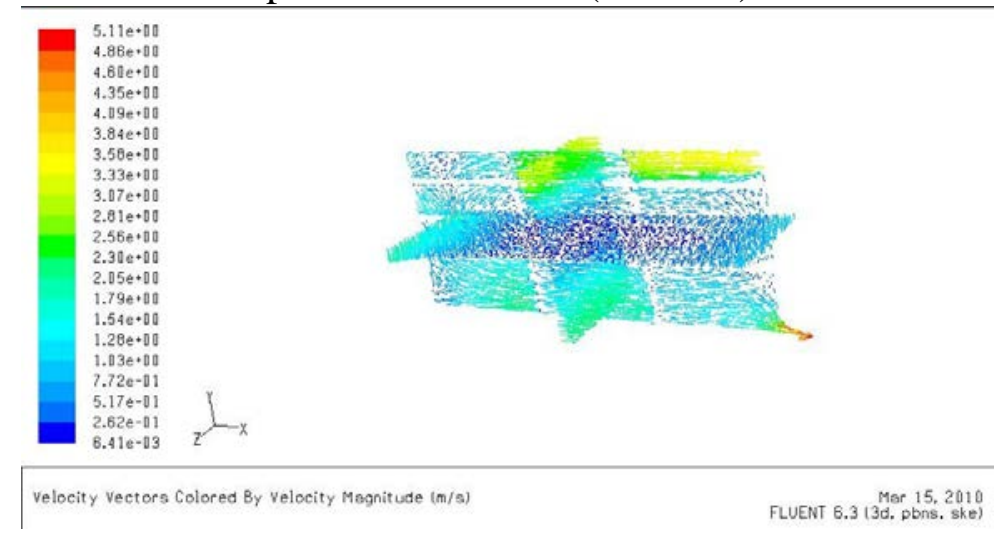

Figure 3. Velocity distribution in curing barn at air supply temperature of $40^{\circ} \mathrm{C}$ and air output of $13000 \mathrm{~m} 3 / \mathrm{h}$ (unit: m/s)

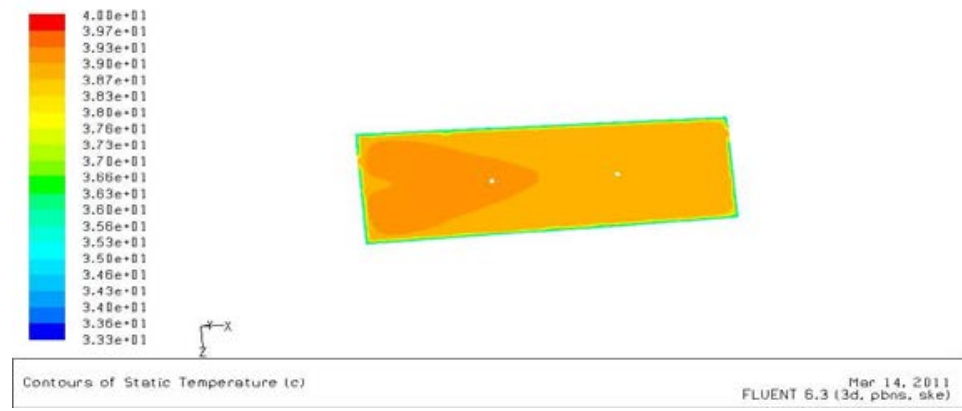

Figure 4. Temperature distribution in the curing cure at the height of $\mathrm{y}=1.6 \mathrm{~m}$ during air supply temperature of $40^{\circ} \mathrm{C}$ and air output of $13000 \mathrm{~m} 3 / \mathrm{h}$ (unit: ${ }^{\circ} \mathrm{C}$ )

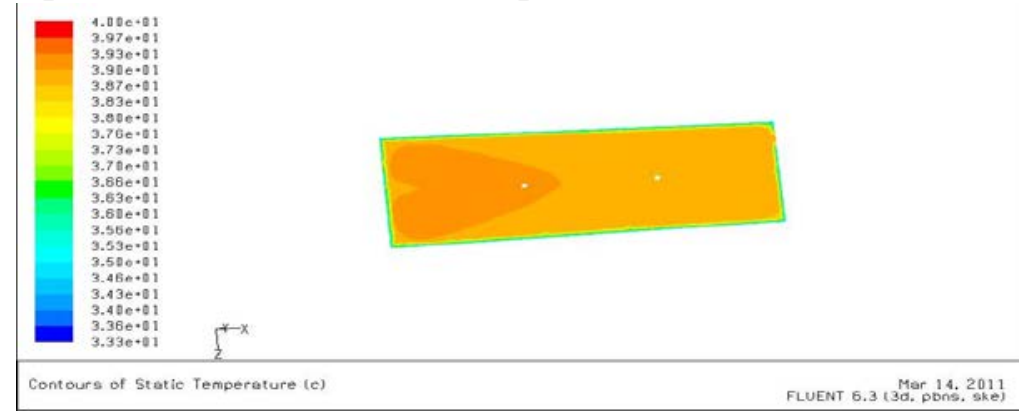

Figure 5. Temperature distribution in the curing cure at the height of $y=1.75 \mathrm{~m}$ during air supply temperature of $40^{\circ} \mathrm{C}$ and air output of $13000 \mathrm{~m} 3 / \mathrm{h}$ (unit: ${ }^{\circ} \mathrm{C}$ ) 


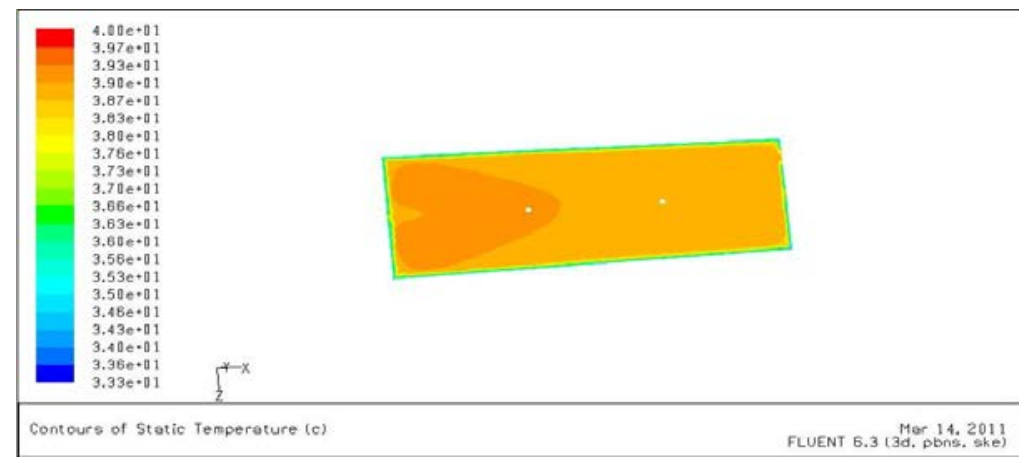

Figure 6. Temperature distribution in the curing cure at the height of $y=2.0 \mathrm{~m}$ during air supply temperature of $40^{\circ} \mathrm{C}$ and air output of $13000 \mathrm{~m} 3 / \mathrm{h}$ (unit: ${ }^{\circ} \mathrm{C}$ )

(1) When supply air temperature is $40{ }^{\circ} \mathrm{C}$ and air output is $13000 \mathrm{~m} 3 / \mathrm{h}$. The temperature distribution in the curing cure is basically kept at $39.7 \sim 40{ }^{\circ} \mathrm{C}$. The temperature near the air supply port is higher, which is kept at $39.7-40^{\circ} \mathrm{C}$. The temperature of air return port is lower, which is kept at $38.7 \sim 39.0{ }^{\circ} \mathrm{C}$. Three heights ar selected for comparison within the scope of flue-cured tobacco, respectively : $\mathrm{y}=1.6 \mathrm{~m}, \mathrm{y}=1.75 \mathrm{~m}$ and $\mathrm{y}=2.0 \mathrm{~m}$. The temperature distribution is $38.7 \sim 39.3{ }^{\circ} \mathrm{C}$; The difference of temperature distribution is about $0.3^{\circ} \mathrm{C}$ on the same plane.

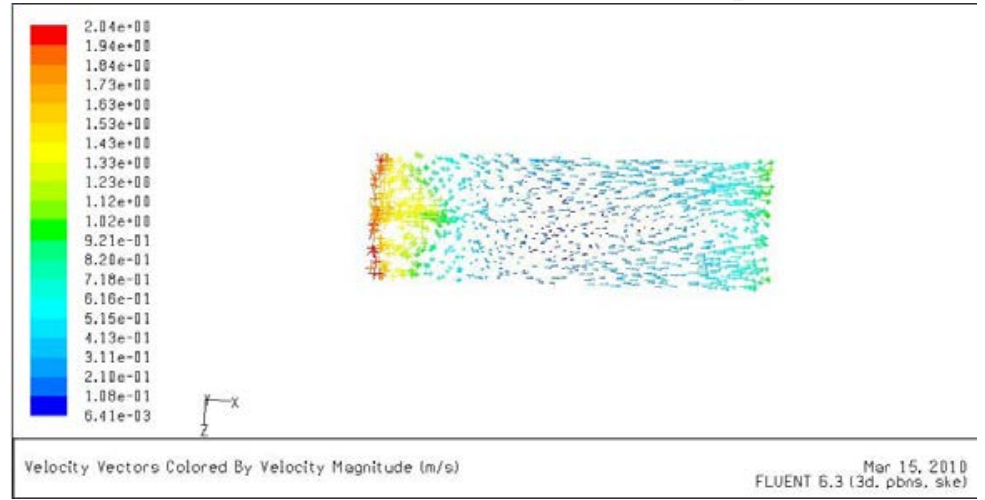

Figure 7. Velocity distribution in curing barn at $\mathrm{y}=1.6 \mathrm{~m}$ during air supply temperature of $40^{\circ} \mathrm{C}$ and air output of $13000 \mathrm{~m} 3 / \mathrm{h}$ (unit: $\mathrm{m} / \mathrm{s}$ )

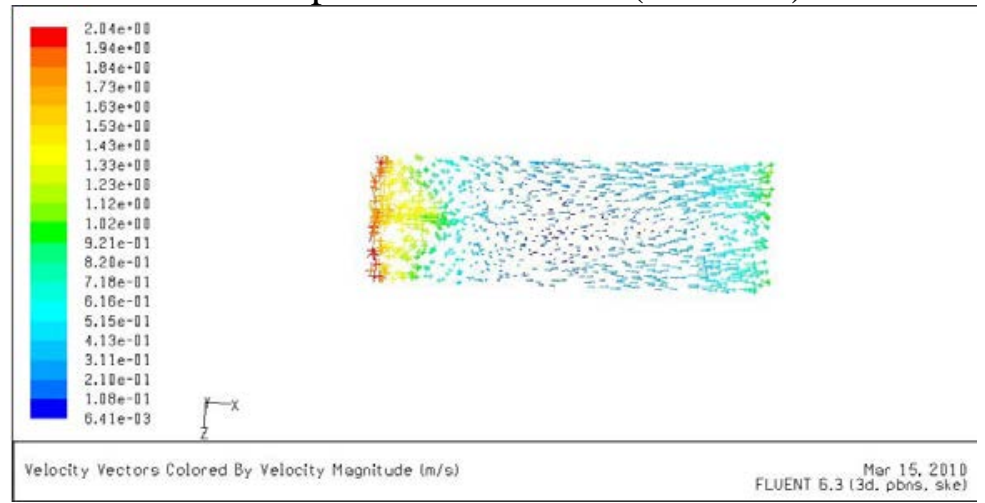

Figure 8. Velocity distribution in curing barn at $y=1.75 \mathrm{~m}$ during air supply temperature of $40^{\circ} \mathrm{C}$ and air output of $13000 \mathrm{~m} 3 / \mathrm{h}$ (unit: $\mathrm{m} / \mathrm{s}$ ) 


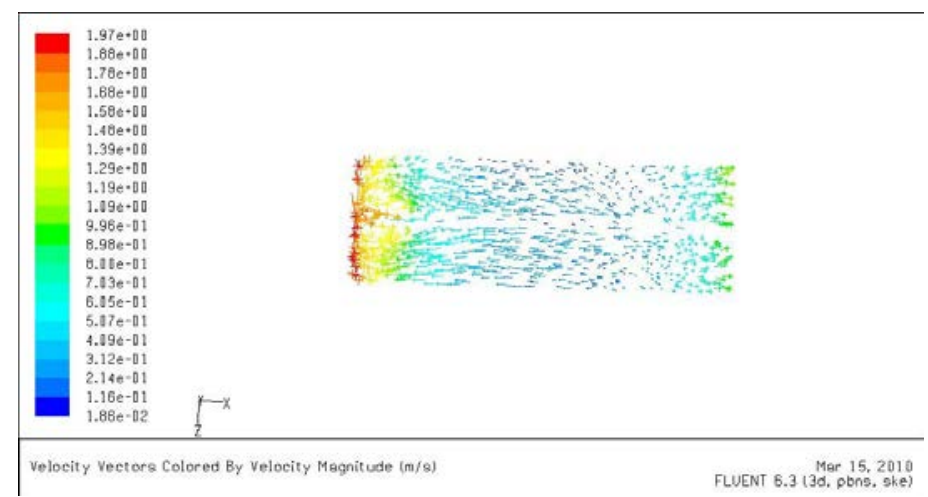

Figure 9. Velocity distribution in curing barn $y=2.0 \mathrm{~m}$ during air supply temperature of $40^{\circ} \mathrm{C}$ and air output of $13000 \mathrm{~m} 3 / \mathrm{h}$ (unit: $\mathrm{m} / \mathrm{s}$ )

(2) When the supply air temperature is $40{ }^{\circ} \mathrm{C}$ and air output is $13000 \mathrm{~m} 3 / \mathrm{h}$, the velocity distribution in the curing barn is $0.00641 \sim 5.11 \mathrm{~m} / \mathrm{s}$; The velocity near of air supply port is $3.33 \sim$ $3.58 \mathrm{~m} / \mathrm{s}$. The velocity of air return port is higher, which is up to $4.86 \sim 5.11 \mathrm{~m} / \mathrm{s}$. Three heights are selected within the flue-cured tobacco scope are compared, respectively $\mathrm{y}=1.6 \mathrm{~m}, \mathrm{y}=1.75 \mathrm{~m}$ and $\mathrm{y}=2.0 \mathrm{~m}$. The velocity is mostly between 0.0309 and $0.436 \mathrm{~m} / \mathrm{s}$ at $\mathrm{y}=1.6 \mathrm{~m}$ along $\mathrm{y}$ axis positive direction within the scope of the flue-cured tobacco area. The velocity is mostly between 0.00614 and $0.413 \mathrm{~m} / \mathrm{s}$ at $\mathrm{y}=1.75 \mathrm{~m}$ along $\mathrm{y}$ axis direction. The velocity is mostly distributed between 0.0186 and $0.507 \mathrm{~m} / \mathrm{s}$ at $\mathrm{y}=2.0 \mathrm{~m}$ along the $\mathrm{y}$ axis positive direction. The air flow velocity in the middle portion of curing barn is smaller at the same height, and the velocity is larger closer to two sides.

(3) Influence of air output on temperature field and velocity field in the curing barn,: the same above method is utilized for respectively calculating several conditions of table 1.

Requirements in the tobacco leaf baking process: the plane temperature is basically uniform and consistent. It is required that the plane temperature difference is $\leqslant 2{ }^{\circ} \mathrm{C}$ at $40{ }^{\circ} \mathrm{C}$ during five-point test. The difference is $\leqslant 3{ }^{\circ} \mathrm{C}$ at $50^{\circ} \mathrm{C}$. The wind velocity within the baking zone is between 0.1 and $0.3 \mathrm{~m} / \mathrm{s}$.

We conclude the follows by calculation: the air output has larger influence on velocity and temperature distribution within the tobacco container. The flow rate in the curing barn $\mathrm{s}$ increased with increase of air output. The air output is larger, the speed is changed prominent. The air output is larger, the temperature distribution is evener. When the air supply temperature is $40{ }^{\circ} \mathrm{C}$, and the air output is reduced to $12000 \mathrm{~m} 3 / \mathrm{h}$, temperature distribution can basically satisfy the requirement. However, velocity distribution can not meet the requirements; When air supply temperature is $40{ }^{\circ} \mathrm{C}$, the air output is more than $18000 \mathrm{~m} 3 / \mathrm{h}$. When the air output is $20000 \sim 24000 \mathrm{~m} 3 / \mathrm{h}$, and the temperature distribution is more ideal. However, velocity distribution can not meet the requirements, therefore the appropriate air output scope is $13000-18000 \mathrm{~m} 3 / \mathrm{h}$.

Tabl 1. Table of Different Air Output Parameters

\begin{tabular}{|l|l|l|}
\hline No. & Air Output $\left(\right.$ unit: $\left.\mathrm{m}^{3} / \mathrm{h}\right)$ & Air supply temperature (unit: K) \\
\hline 1 & 12000 & 40 \\
\hline 2 & 14000 & 40 \\
\hline 3 & 16000 & 40 \\
\hline 4 & 18000 & 40 \\
\hline 5 & 20000 & 40 \\
\hline 6 & 22000 & 40 \\
\hline 7 & 24000 & 40 \\
\hline
\end{tabular}

\section{Conclusion}

Bulk standard curing barn is regarded as simulation research object. two-equation 3D turbulent flow model is adopted for numerical simulation on tobacco container temperature and air flow distribution of the bulk curing barn. The simulation result table is shown as follows:

(1) The air output has larger influence on velocity and temperature distribution in the tobacco 
container, wherein the influence on velocity is more prominent.

(2) The air output is increased. The flow rate increase within the tobacco can make the temperature field distribution more homogeneous.

(3) When upper supply and low return air supply mode is adopted in the bulk curing barn, and the air output is $13000-18000 \mathrm{~m} 3 / \mathrm{h}$, the requirement of tobacco baking process on indoor air flow rate and temperature distribution can be better satisfied.

\section{References}

[1] Xu Xiuhong, Sun Fushan, Wang Yong, etc. Discussion on research application status and development direction in the bulk curing barn. Chinese Tobacco Science, 2008, (4): 54-56, 61.

[2] Li Junhong, Zou Zhijun, Luo Hang, etc. Test measurement and numerical simulation on indoor flow field and temperature field. Essay Collection of 2005Fluent Chinese User Meeting 2008: 122-126.

[3] Tao Wenquan. Numerical heat transfer. Xi'an: Xi'an Jiaotong University Press, 2001:344-349.

[4] Zhang Caisan. Fu Bin. Use of ESC numerical simulation bus compartment without temperature field and air flow field [J]. Vehicle and Power Technology 2004, (4):45-48.

[5] LIAN Zhi-wei,ZHANG Gui-rong,YE Xiao-jiang. Evaluation of air distribution in an air conditioned railway carriage. Journal of Shanghai Jiaotong University, 2004,38(6:)961-966.

[6] John D Jr.Computational Fluid Dynamics. Beijing: Tsinghua University Press, 2002:88-90.

[7] Du Zixue, Shen Xubing, Liu Yingqing. Research on temperature field computer simulation method in minibus. Chinese Manufacturing Informatization, 2003, 32(4): 68-69, 71.

[8] Xiang Liping, Wang Hanqing, Li Kongqing, etc. Numerical simulation on indoor air flow and temperature field of automobile air-conditioned bus. Refrigeration and Air Conditioning, 2008, 22(6): 41-44.

[9] Zang Yunlei, Chen Shuling. Numerical calculation of indoor temperature field and flow field of metro passenger compartment by FLUENT software. Essay Collection of the Third Engineering Computational Fluid Dynamics Conference [C], Beijing: Science Publishing History, 1988.

[10] Zhong Ke, Chi Jinhua, Zhou Lei, etc. Simulation and analysis on indoor temperature field and PMV distribution under different air exchange frequencies [EB/OL]. http://wenku.baidu.com/view/f84aee5f804d2b160b4ec066.html, 2010-09-10. 